\title{
The Nod2 Agonist Muramyl Dipeptide Cooperates with the TLR4 Agonist Lipopolysaccharide to Enhance IgG2b Production in Mouse B Cells
}

\author{
Sang-Hoon Lee, ${ }^{1}$ Jong-Hwan Park, ${ }^{2}$ and Seok-Rae Park $\mathbb{D}^{1,3}$ \\ ${ }^{1}$ Department of Microbiology, Myunggok Medical Research Institute, College of Medicine, Konyang University, \\ Daejeon 35365, Republic of Korea \\ ${ }^{2}$ Laboratory Animal Medicine, College of Veterinary Medicine, Chonnam National University, Gwangju 61186, Republic of Korea \\ ${ }^{3}$ Priority Research Center, Myunggok Medical Research Institute, College of Medicine, Konyang University, \\ Daejeon 35365, Republic of Korea
}

Correspondence should be addressed to Seok-Rae Park; srpark@konyang.ac.kr

Received 24 May 2019; Revised 25 September 2019; Accepted 19 October 2019; Published 26 November 2019

Guest Editor: Riadh Ben Mansour

Copyright ( 2019 Sang-Hoon Lee et al. This is an open access article distributed under the Creative Commons Attribution License, which permits unrestricted use, distribution, and reproduction in any medium, provided the original work is properly cited.

\begin{abstract}
Many studies have shown that Toll-like receptors (TLRs) and Nod-like receptors (NLRs) were expressed in B cells and their signaling affects B cell functions. Nonetheless, the roles played by these receptors in B cell antibody (Ab) production have not been completely elucidated. In the present study, we examined the effect of the Nod2 agonist muramyl dipeptide (MDP) in combination with the TLR4 agonist lipopolysaccharide (LPS), a well-known B cell mitogen, on B cell viability, proliferation, and activation, and $\mathrm{Ab}$ production by in vitro culture of purified mouse spleen resting $\mathrm{B}$ cells. MDP combined with LPS to reinforce $\mathrm{B}$ cell viability, proliferation, and activation. Moreover, MDP enhanced LPS-induced IgG2b production, germline $\gamma 2 \mathrm{~b}$ transcript (GLT $\gamma 2 \mathrm{~b})$ expression, and surface IgG2b expression. In an experiment with Nod2- and TLR4-deficient mouse B cells, we observed that the combined effect of MDP and LPS is dependent on Nod2 and TLR4 receptors. Furthermore, the combined effect on B cell viability and IgG2b switching was not observed in Rip2-deficient mouse cells. Collectively, this study suggests that Nod2 signaling enhances TLR4-activated B cell proliferation, IgG2b switching, and IgG2b production.
\end{abstract}

\section{Introduction}

Pattern recognition receptors such as Toll-like receptors (TLRs), Nod-like receptors (NLRs), and C-type lectin receptors (CLRs) recognize specific conserved bacterial structures (pathogen-associated molecular patterns). TLR signaling can directly affect $\mathrm{B}$ cell functions, even without the support of T cells [1-4]. We recently reported that TLR $1 / 2$ agonist Pam3CSK4 and TLR7 agonist imiquimod directly inhibit IgG1 and IgE class switching, respectively, in activated mouse $B$ cells $[5,6]$. In addition, we found that Dectin-1 (a type of CLR) agonist selectively induced IgG1 class switching by TLR4 agonist lipopolysaccharide (LPS)-activated mouse B cells $[7,8]$. Many studies have shown that TLR signaling interplays with other receptor signaling such as other TLRs, $B$ cell receptor (BCR), and CD40 signaling in B cells [9-14].
For instance, TLR2 stimulation arrests TLR4 agonist LPSpromoted B cell maturation [15]; BCR signaling synergizes with TLR signaling for activation-induced cytidine deaminase (AID) expression and Ig class switch recombination (CSR) by B cells [16]. Thus, TLRs play various roles in B cell activation, differentiation, and function.

However, the roles played by NLRs (Nod1, Nod2, NLRC4, NLRP3, etc.) in B cells remain to be elucidated. The effects of Nod1 and Nod2 stimulation on B cell activation have been investigated in only a few studies: Cohen and Parant reported that Nod2 agonist muramyl dipeptide (MDP) increases surface Ig (membrane $\kappa$-light chain) expression and enhances the response to LPS in the mouse pre-B cell line 70Z/3 [17]; Petterson et al. reported that Nod1 or Nod2 stimulation augments BCR- or TLRinduced human B cell activation (proliferation, viability, 


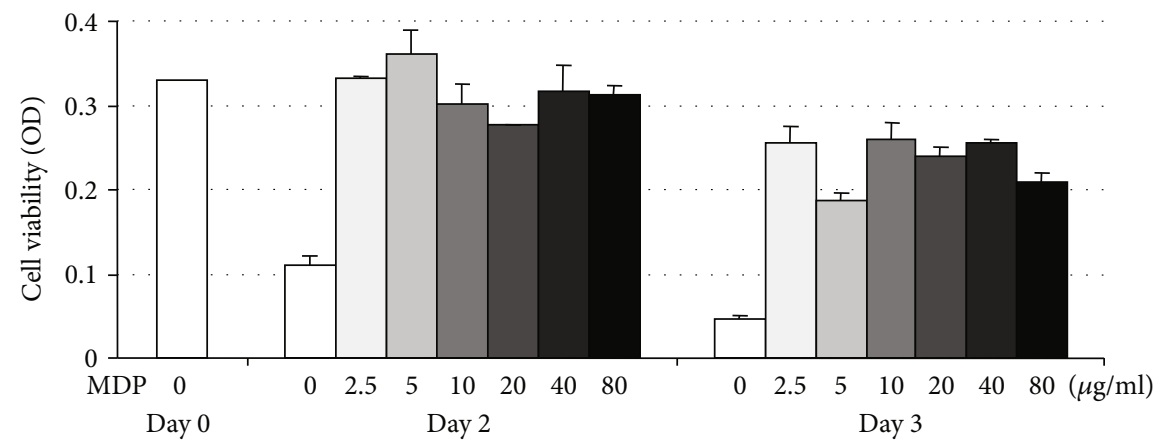

(a)

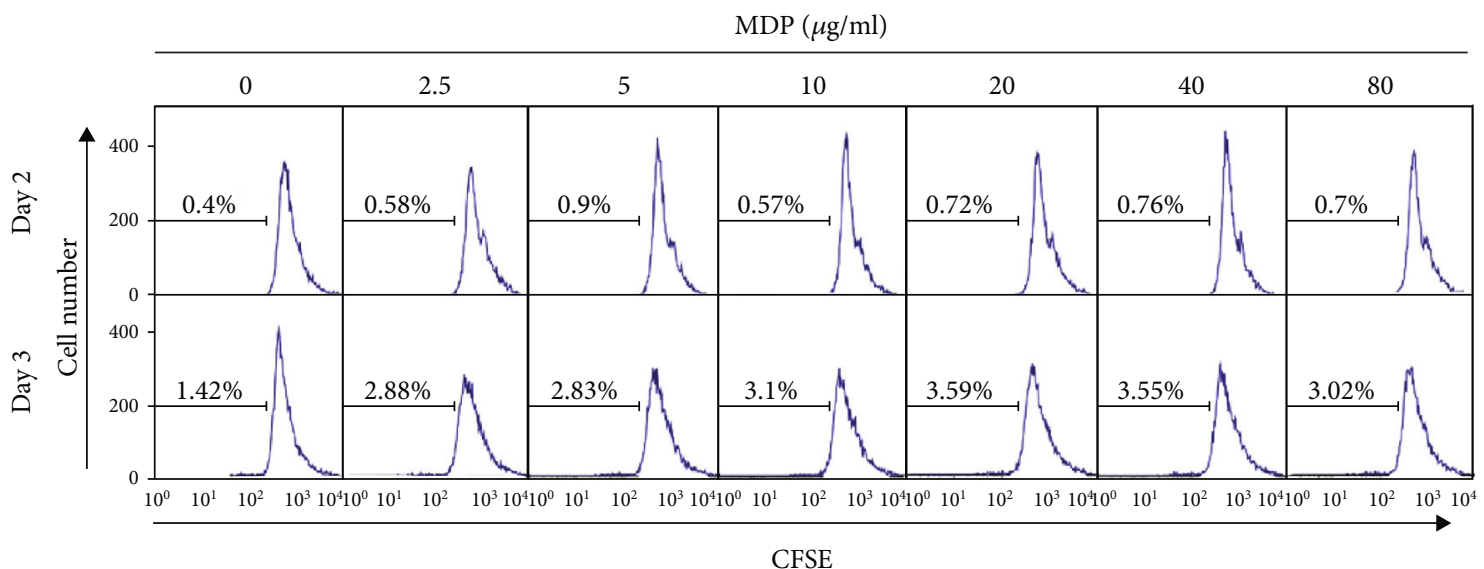

(b)

FIgURE 1: MDP sustains B cell viability in vitro, but MDP itself hardly induces B cell proliferation. Resting B cells were stimulated with the indicated MDP concentrations. After 2 and 3 days of culture, cell viability was measured by (a) EZ-Cytox assay and (b) cell proliferation was measured by CFSE assay. Data shown are representative of two independent experiments.

and expression of cell surface markers) independently of physical $\mathrm{T}$ cell assistance [18, 19].

In the present study, to further elucidate the role of Nod2 in $\mathrm{B}$ cell response, we directly stimulated mouse resting B cells with MDP in the absence and presence of LPS in vitro and analyzed B cell viability, proliferation, activation, antibody $(\mathrm{Ab})$ production, and Ig class switching.

\section{Materials and Methods}

2.1. Animals. Wild-type (WT) C57BL/6 mice were purchased from Damool Science (Daejeon, Korea). TLR4-deficient $\left(\mathrm{Tlr} 4^{-/-}\right)$, Nod2-deficient (Nod2 $2^{-/-}$), and Rip2-deficient (Rip2${ }^{\prime-}$ ) mice with a C57BL/6 background were purchased from Jackson Laboratory (Bar Harbor, ME, USA). Mice were maintained on an $8: 16 \mathrm{~h}$ light:dark cycle in an animal environmental control chamber. Eight- to twelve-week-old mice were used, and animal care was provided in accordance with the guidelines of the Institutional Animal Care and Use Committee of Konyang University.

2.2. Cell Culture and Reagents. The mouse B cell lines L10A6.2 (surface $\mu^{+}$, mature B cell line) and A20.3 (surface $\gamma 2 \mathrm{a}^{+}$) were provided by Dr. J. Stavnezer (University of Massachusetts Medical School, Worcester, MA, USA). The mouse B lymphoma cell line CH12F3-2A (surface $\mu^{+}$) was provided by Dr. T. Honjo (Kyoto University, Kyoto, Japan). Mouse spleen resting B cells were obtained by depletion of $\mathrm{CD} 43^{+}$cells using anti-CD43 microbeads and high-gradient magnetic cell separation according to the manufacturer's instruction (MACS; Miltenyi Biotec, Bergisch Gladbach, Germany) as previously described [5]. The purity of resting $\mathrm{B}$ cells $\left(\mathrm{CD} 43^{-} \mathrm{B} 220^{+}\right.$) was assessed using FACSCalibur (BD Biosciences, San Jose, CA, USA) following staining of the cells with anti-CD43 FITC (eBioscience, San Diego, CA, USA) and anti-B220 PE (BD Biosciences) (Supplementary Figure 1(a)). The cells were cultured at $37^{\circ} \mathrm{C}$ in a humidified $\mathrm{CO}_{2}$ incubator (Forma Scientific, Marietta, OH, USA) in RPMI-1640 medium (Welgene, Daegu, Korea) supplemented with $10 \%$ fetal bovine serum (PAA Laboratories, Etobicoke, ON, Canada). The cells were stimulated with LPS (ultrapure LPS, E. coli 0111:B4; InvivoGen, San Diego, CA, USA), MDP (InvivoGen), and iE-DAP (InvivoGen). The mouse macrophage cell line RAW264.7 was cultured in DMEM (Welgene) containing $2 \mathrm{mM}$ L-glutamine, $100 \mathrm{U} / \mathrm{mL}$ penicillin, $100 \mu \mathrm{g} / \mathrm{mL}$ streptomycin, and $10 \%$ fetal bovine serum in a humidified $\mathrm{CO}_{2}$ incubator. Anti-mouse IgG2b- 


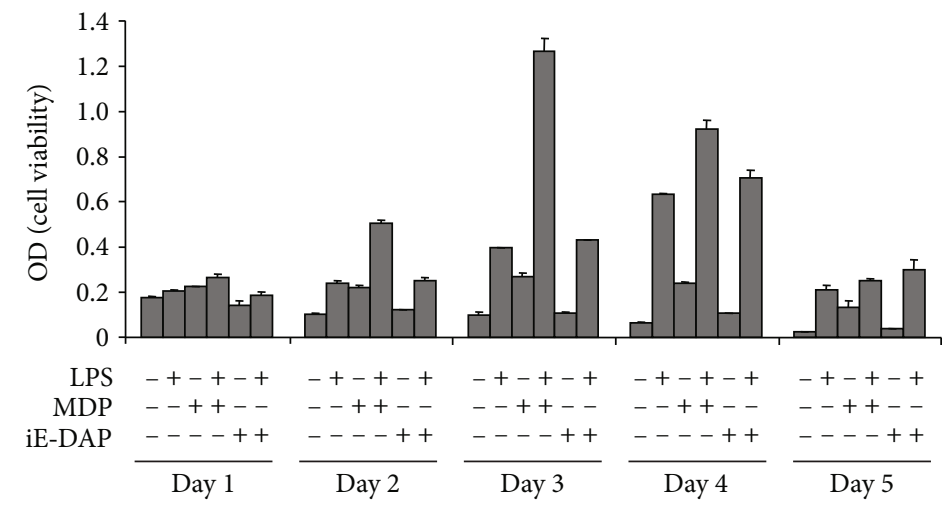

(a)
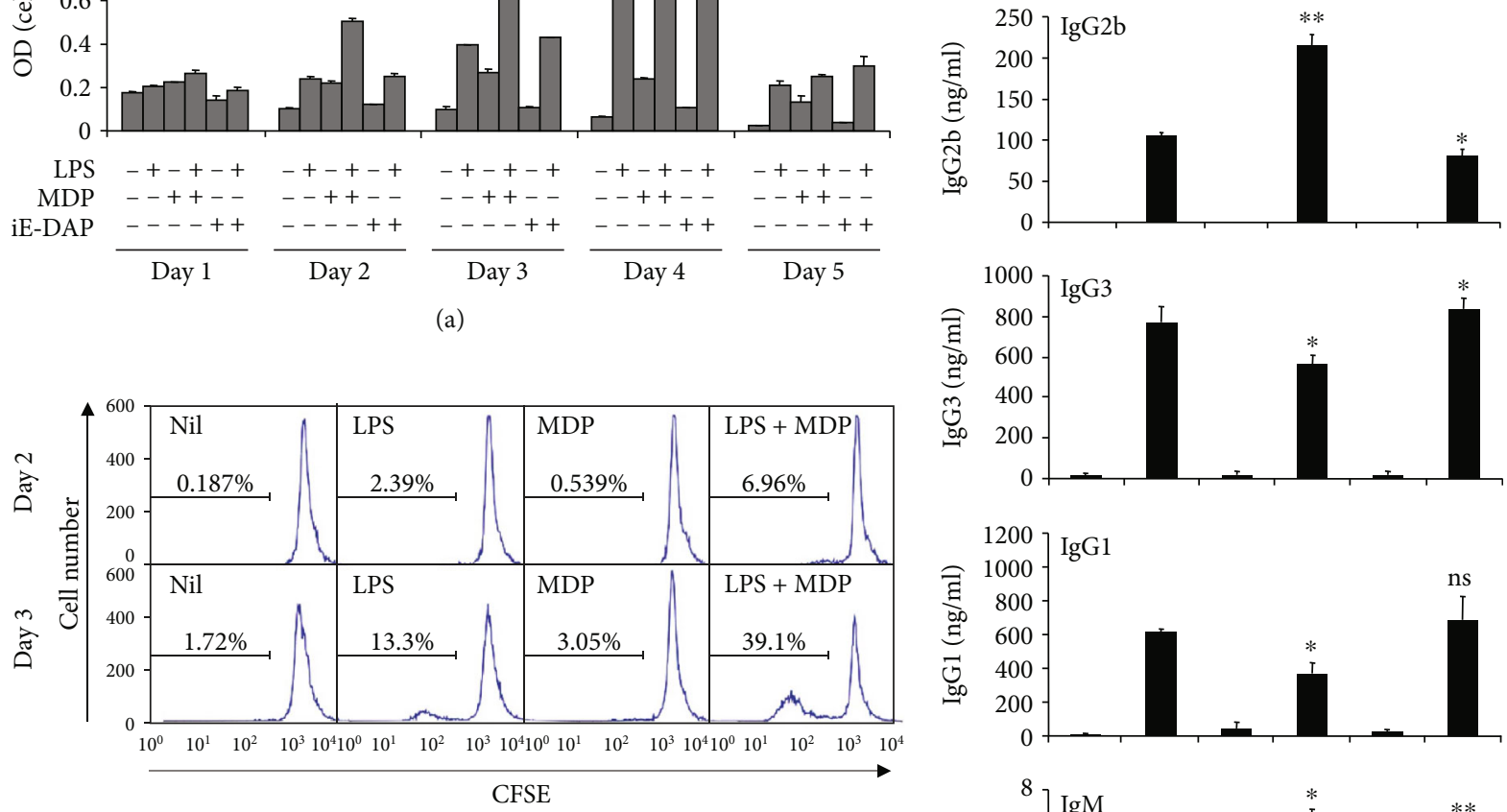

(b)

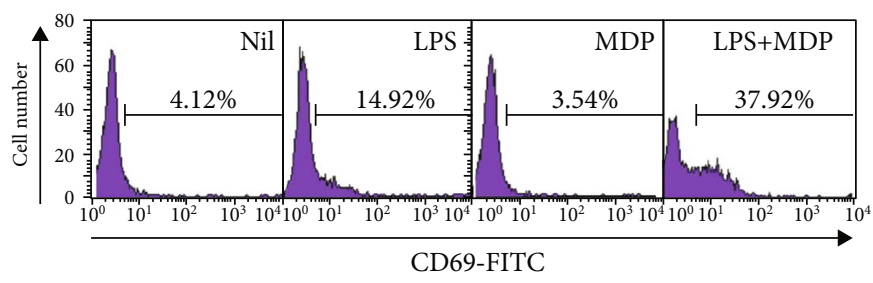

(c)
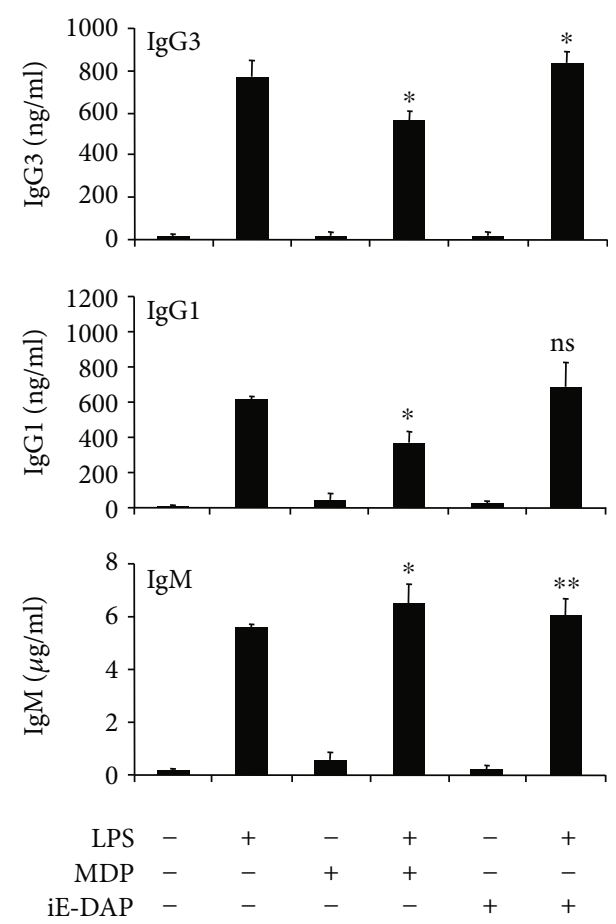

(d)

FIGURE 2: Combined effects of LPS and MDP on B cell viability, proliferation, activation, and Ab production. Resting B cells were stimulated with $\operatorname{MDP}(10 \mu \mathrm{g} / \mathrm{mL})$ or iE-DAP $(10 \mu \mathrm{g} / \mathrm{mL})$ in the presence or absence of LPS $(1 \mu \mathrm{g} / \mathrm{mL})$. (a) Cell viability was measured by EZ-Cytox assay at the indicated time points (days). Data presented are means of duplicate samples with ranges (bars). (b) After 2 and 3 days of culture, cell proliferation was measured using CFSE assay. (c) After 2 days of culture, B cell activation was determined by surface CD69 expression. (d) After 7 days of culture, supernatants were harvested, and the levels of Ab production were measured using isotype-specific ELISA. Data presented are the means \pm SEM from three independent experiments. ${ }^{*} p<0.05,{ }^{* *} p<0.01$, SEM: standard error of the mean; ns: not significant.

$\mathrm{PE}$ and anti-mouse IgG3-PE were purchased from Southern Biotech (Birmingham, AL, USA). Anti-mouse IgM-PE was obtained from eBioscience.

2.3. Cell Viability, Proliferation, and Activation Assays. Cell viability was determined using the EZ-Cytox cell viability assay (DaeilLab Service Co., Ltd., Seoul, Korea) according to the manufacturer's instructions [8]. For the cell proliferation assay, purified mouse resting $B$ cells were labeled with CFSE (eBioscience) and then supplemented with MDP, iEDAP, and LPS. CFSE dilution was measured by counting 10,000 cells with the FACSCalibur. For the cell activation assay, cultured cells were stained with anti-CD69-FITC (BD Biosciences), and the expression levels were analyzed by flow cytometry (FACSCalibur).
2.4. Isotype-Specific ELISAs. Antibodies produced in B cell cultures were detected using isotype-specific ELISAs as previously described [8].

2.5. RNA Isolation and RT-PCR. RNA isolation and RT-PCR were performed as previously described [6]. The PCR primers (Supplementary Table 1) were synthesized by Bioneer (Daejeon, Korea). PCR for $\beta$-actin was performed in parallel to normalize for cDNA concentrations within each set of samples. PCR products were resolved by electrophoresis on $2 \%$ agarose gels. Semiquantitative RTPCR analysis was performed using cDNA dilutions.

2.6. Flow Cytometric Analysis. Surface staining was performed with anti-mouse IgG2b-PE, anti-mouse IgG3-PE, 

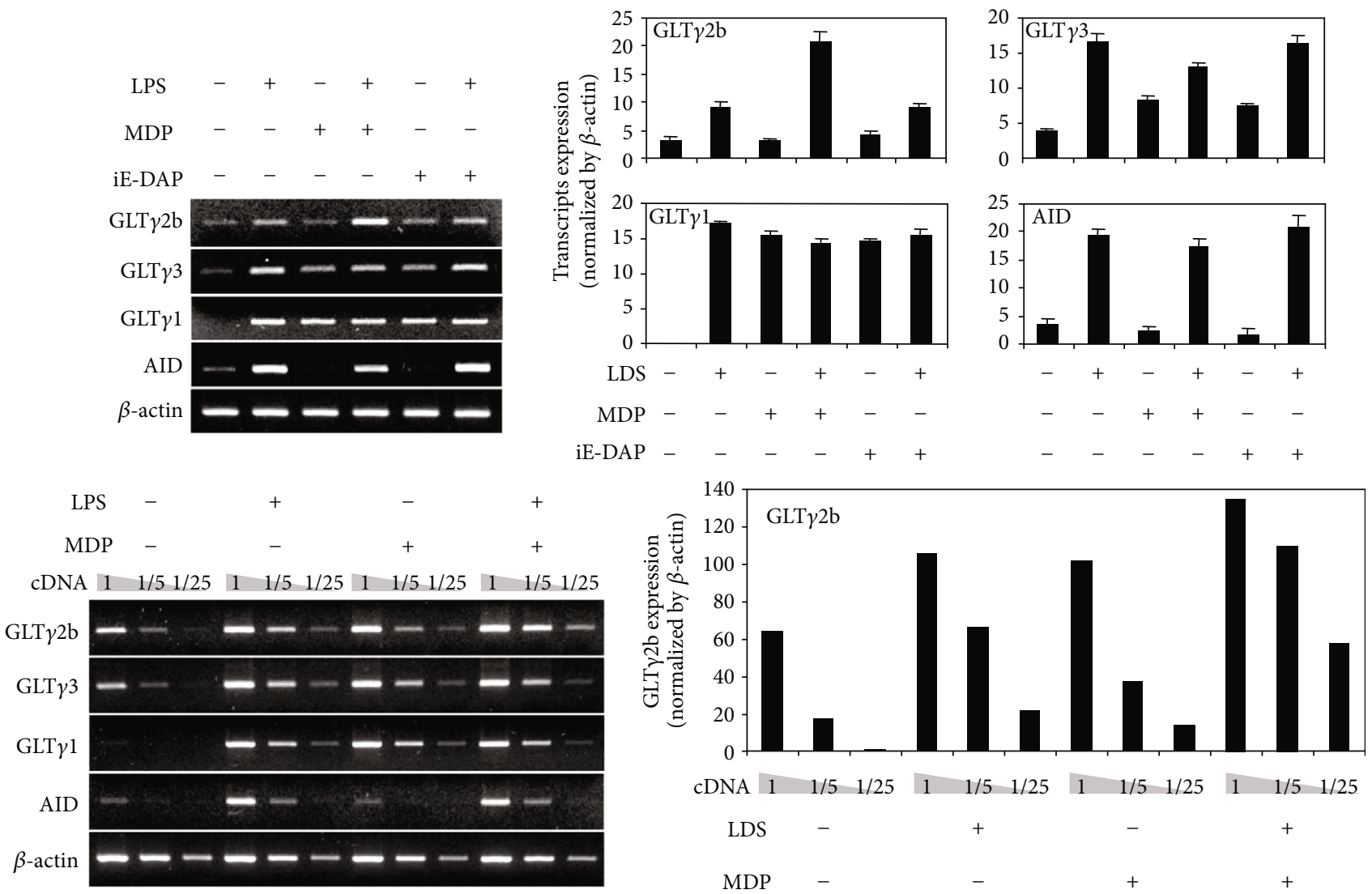

FIGURE 3: Combined effects of LPS and MDP on the expression of germline transcripts and AID mRNA. Resting B cells were stimulated with $\operatorname{MDP}(10 \mu \mathrm{g} / \mathrm{mL})$ and iE-DAP $(10 \mu \mathrm{g} / \mathrm{mL})$ in the presence or absence of LPS $(1 \mu \mathrm{g} / \mathrm{mL})$. After 2.5 days of culture, RNAs were isolated, and the levels of germline transcripts and AID mRNA were measured by RT-PCR. The levels of germline transcripts and AID mRNA were measured by semiquantitative RT-PCR with $1 / 5$ and $1 / 25$ diluted cDNA (lower panel). The graphs show relative transcript levels normalized to the expression of $\beta$-actin cDNA by ImageJ ( $\mathrm{NIH}$, Bethesda, MD, USA) analysis. Densitometric data are averages of two independent experiments with ranges (bars).

or anti-mouse IgM-PE in the dark for $30 \mathrm{~min}$ at $4^{\circ} \mathrm{C}$, and surface Ig-expressing $\mathrm{B}$ cells were analyzed by flow cytometry (FACSCalibur). Dead cells were excluded from analysis using Zombie Red ${ }^{\mathrm{TM}}$ Fixable Viability Kit according to the manufacturer's instruction (BioLegend, San Diego, CA).

2.7. Statistical Analysis. Statistical differences between experimental groups were determined by analysis of variances. All $p$ values were calculated using unpaired 2-tailed Student's $t$ -tests to assess statistical significance.

\section{Results and Discussion}

3.1. Dosage Effect of Nod2 Agonist MDP on B Cell Viability and Proliferation. First, to determine the direct effect of the Nod2 agonist MDP on B cell viability and proliferation, we purified resting B cells from mouse spleen (Supplementary Figure 1(a)) and treated them with MDP. The resting B cells expressed Nod1 and Nod2 as well as TLR4 (Supplementary Figure 1(b)). The RAW264.7 mouse macrophage cell line was used as a positive control for TLR and NLR expression. Resting B cells could not survive in the absence of stimuli in vitro and died (Figure 1(a), white bars). MDP treatment sustained B cell viability but did not increase it in a dose-dependent manner. MDP very slightly induced B cell proliferation (Figure 1(b)). However, MDP alone did not induce any $\mathrm{Ab}$ production (data not shown). These results suggest that MDP sustains B cell viability, but MDP itself hardly induces B cell proliferation and plasma cell differentiation.

3.2. Nod2 Agonist MDP but Not Nod1 Agonist iE-DAP Combines with TLR4 Agonist LPS to Induce B Cell Viability and Proliferation and IgG2b Production. New functions in innate immune cells have been reported for the crosstalk between TLRs and NLRs [20-22]. There is a synergistic stimulation of human monocytes and dendritic cells by TLR4 and Nod1- and Nod2-activating agonists [23]. Furthermore, Nod2 is involved in TLR4-mediated signaling of inflammation regulation [24, 25]. LPS stimulates TLR4 and is a well-known mitogen for mouse B cells [26, 27]. TLR4 on B cells recognizes LPS and stimulates B cell proliferation, differentiation, and Ig CSR. LPS in vitro stimulation 

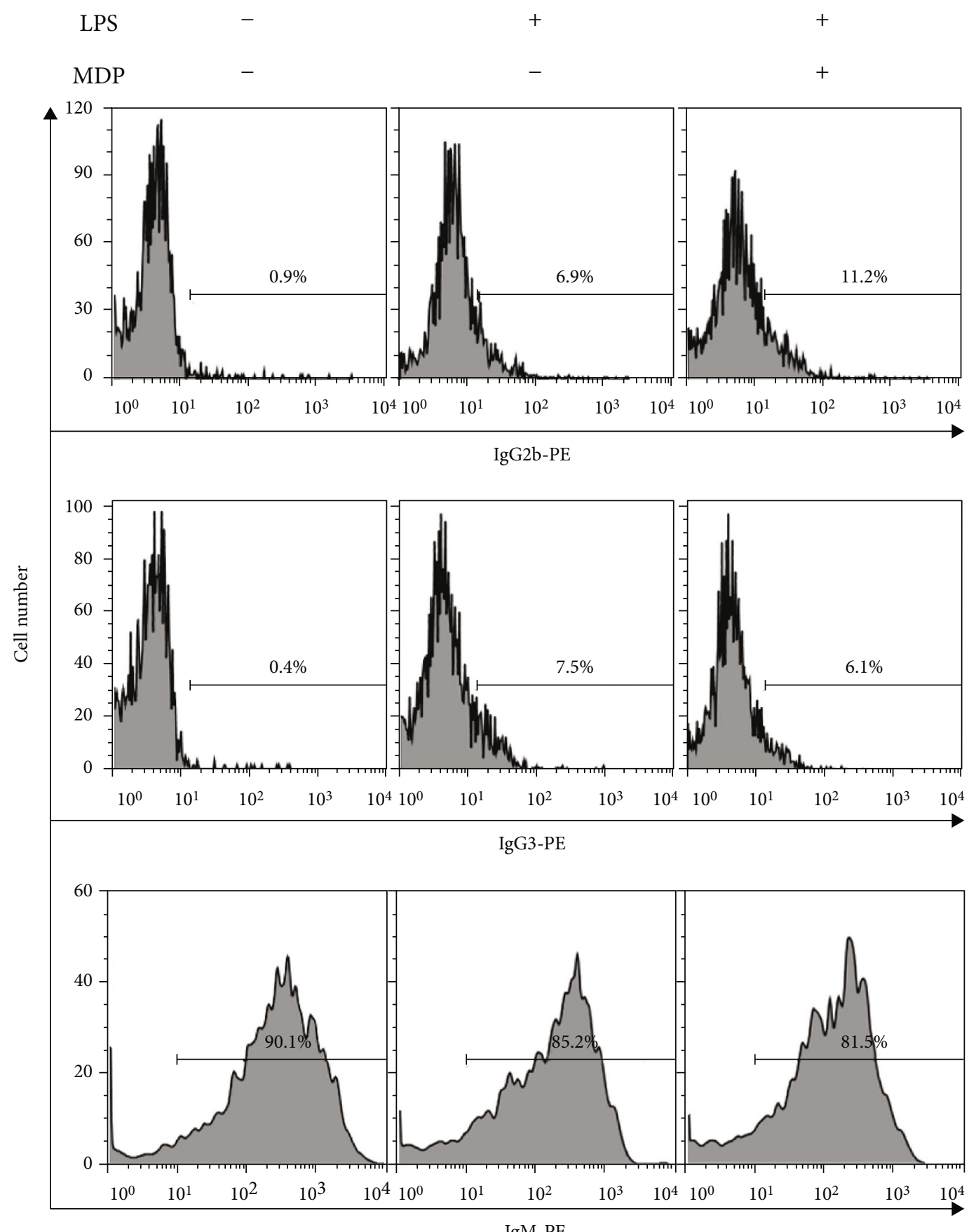

FIgURE 4: Combined effects of LPS and MDP on surface Ig expression. Resting B cells were stimulated with LPS (1 $\mu \mathrm{g} / \mathrm{mL})$ and MDP $(10 \mu \mathrm{g} / \mathrm{mL})$. After 4 days of culture, cells were stained with anti-IgG2b-PE, anti-IgG3-PE, or anti-IgM-PE, and surface Ig expression was analyzed by flow cytometry.

increases $\operatorname{IgG} 2 \mathrm{~b}$ and $\operatorname{IgG} 3$ production through $\operatorname{IgG} 2 \mathrm{~b}$ and IgG3 class switching, respectively, by mouse B cells [4, 28-33]. Therefore, we investigated the combined effect of TLR4 agonist LPS and Nod2 agonist MDP or Nod1 agonist iE-DAP on $\mathrm{B}$ cell viability, proliferation, activation, and $\mathrm{Ab}$ production. Resting B cells were stimulated with MDP or iE-DAP in the presence or absence of LPS. After 2 and 3 days of culture, LPS-induced cell viability was significantly enhanced by MDP but not by iE-DAP (Figure 2(a)). In addition, MDP reinforced LPS-induced cell proliferation (Figure 2(b)). These results indicate that MDP combined with LPS to induce B cell viability and proliferation, while iE-DAP does not. Further, MDP enhanced LPS-induced expression of $\mathrm{CD} 69$, which is an activation marker (Figure 2(c)). Next, we examined the effect of MDP on LPS-induced $\mathrm{Ab}$ production, particularly IgG2b and IgG3 production. MDP increased LPS-induced IgG2b production but decreased LPS-induced IgG3 and IgG1 production 


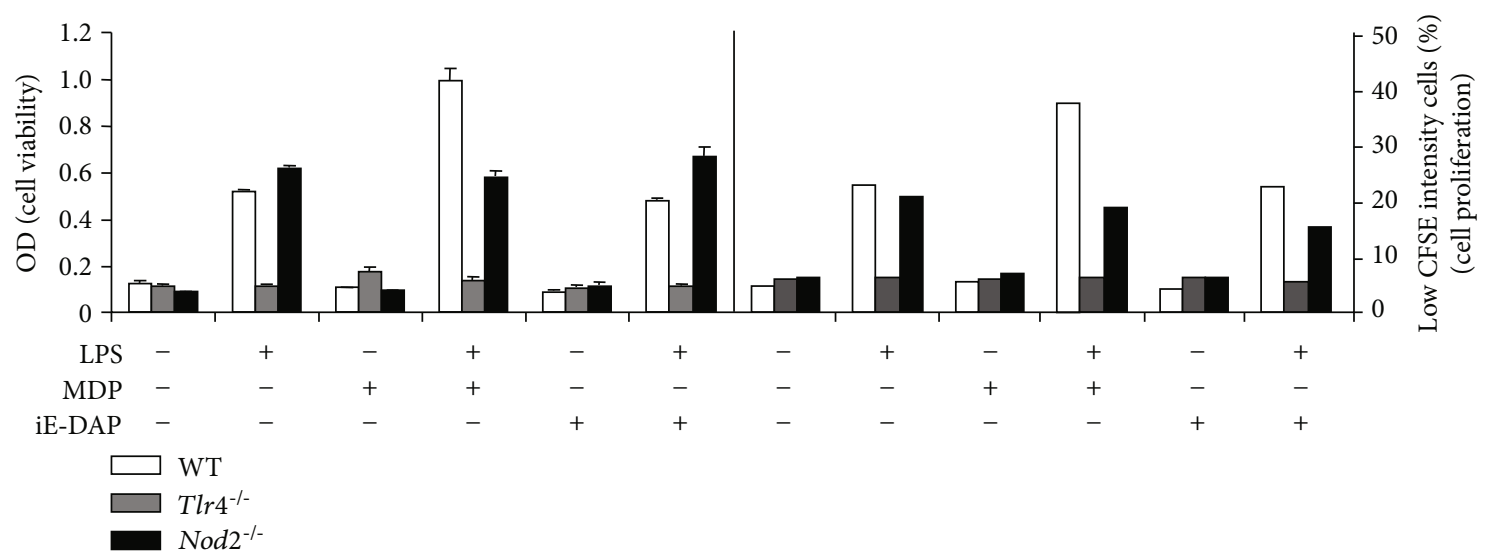

(a)
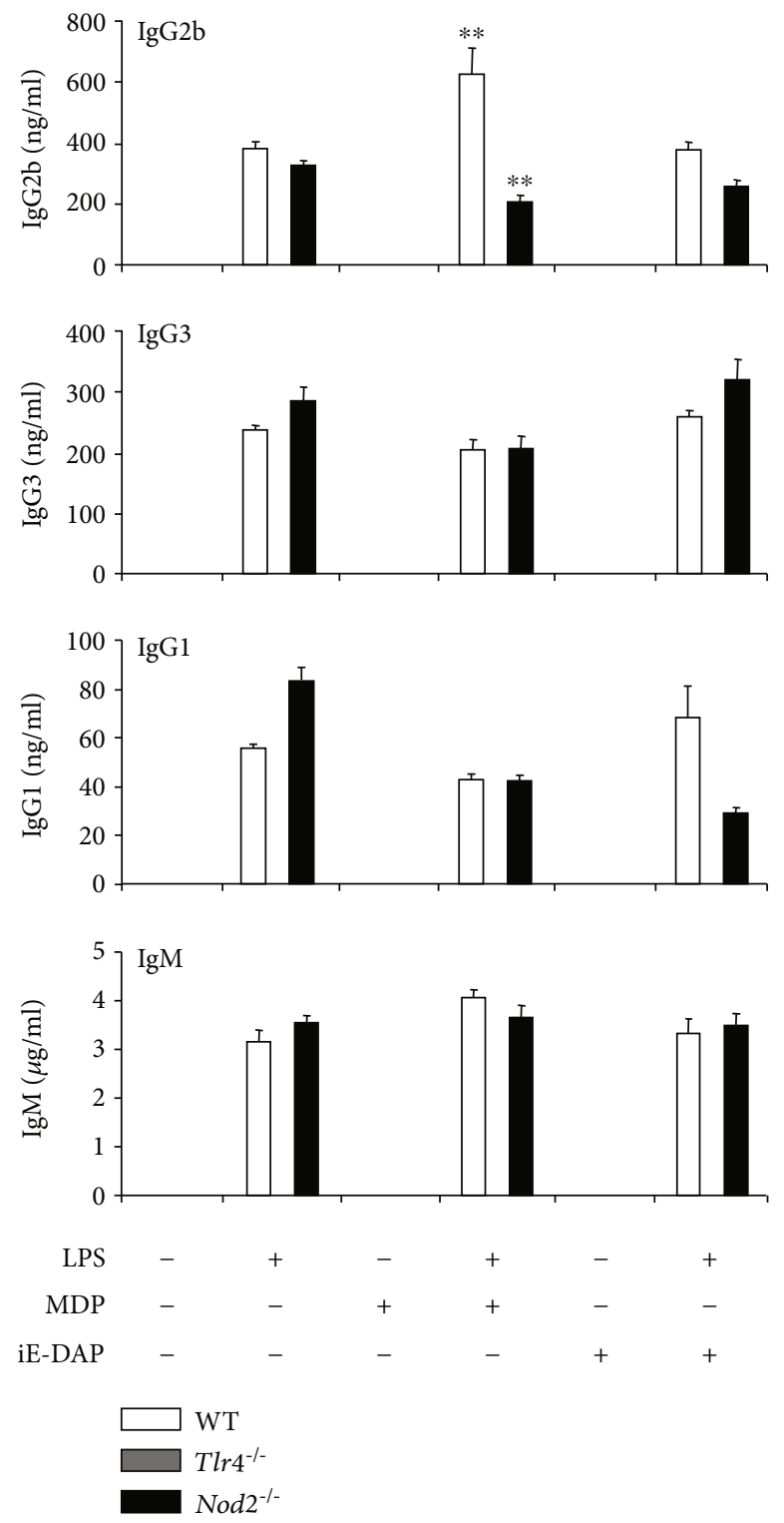

(b)

Figure 5: Continued. 

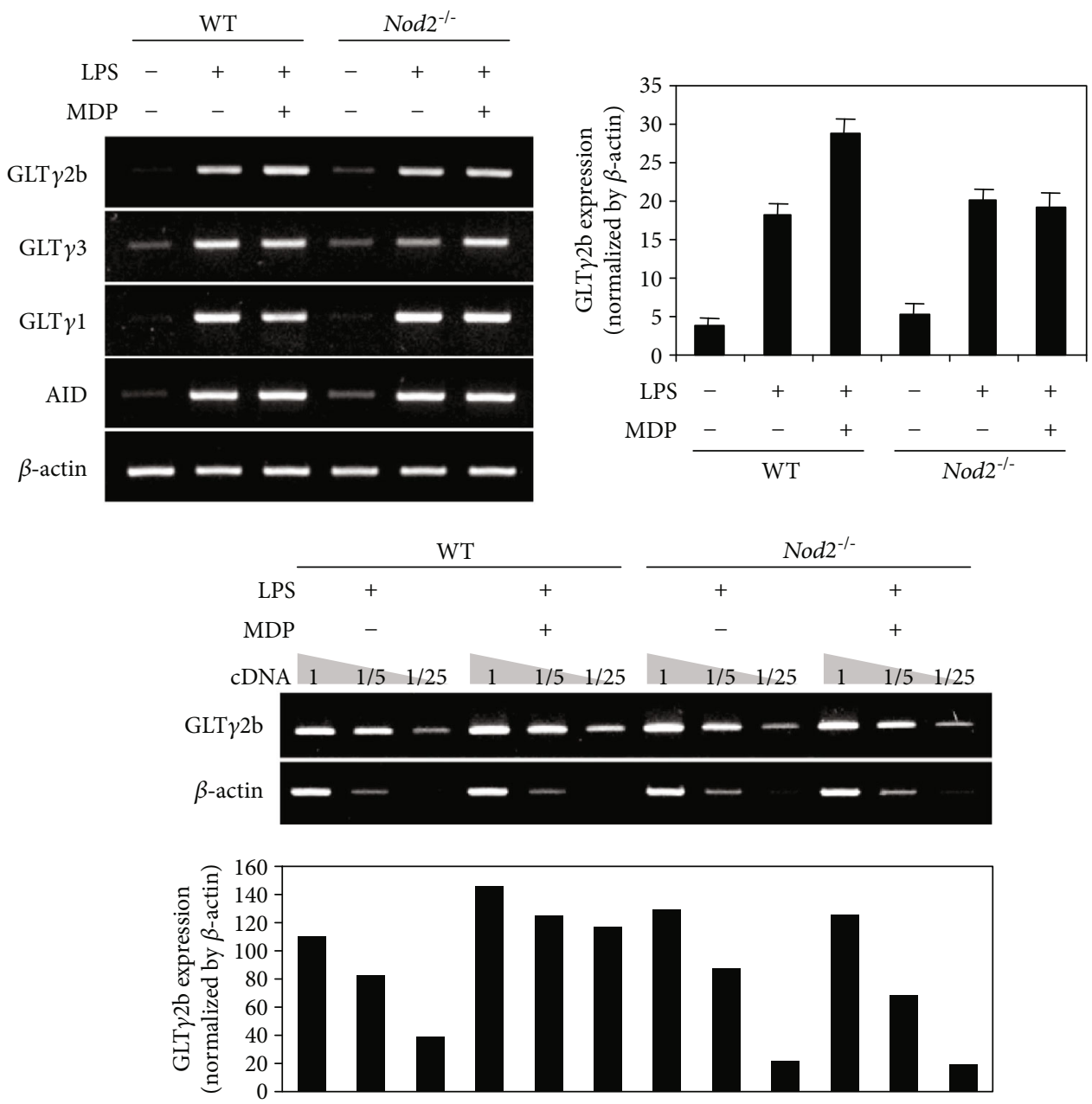

(c)

FIGURE 5: Effects of LPS and MDP on cell viability, proliferation, and Ab production and germline transcripts expression in TLR4- and Nod2deficient B cells. Resting B cells were purified from wild-type (WT), TLR4-deficient (Tlr4 $\left.4^{-/-}\right)$, and Nod2-deficient (Nod2 ${ }^{-/-}$) B cells and stimulated with MDP $(10 \mu \mathrm{g} / \mathrm{mL})$ and iE-DAP $(10 \mu \mathrm{g} / \mathrm{mL})$ in the presence or absence of LPS $(1 \mu \mathrm{g} / \mathrm{mL})$. (a) After 2 and 3 days of culture, cell viability (OD) was measured by EZ-Cytox assay kit, and cell proliferation was measured by CFSE assay. Low CFSE intensity cell (\%) means the proportion of proliferating cells. (b) After 7 days of culture, supernatants were harvested, and the levels of Ab production were measured by isotype-specific ELISA. Data shown are averages of triplicate cultures with SEM error bars. SEM: standard error of the mean. ${ }^{* *} p<0.01$. (c) After 2.5 days of culture, RNAs were isolated and the levels of germline transcripts and AID mRNA were measured by RTPCR. The levels of germline transcripts and AID mRNA were measured by semiquantitative RT-PCR with 1/5 and 1/25 diluted cDNA (c, lower panel). The graphs show relative GLT $\gamma 2 \mathrm{~b}$ level normalized to $\beta$-actin cDNA expression using ImageJ, and data are averages of two independent experiments with ranges (bars).

(Figure 2(d)). iE-DAP had no significant effect on LPSinduced $\mathrm{Ab}$ production. Instead, iE-DAP decreased LPSinduced IgG2b production. These results indicate that MDP combines with LPS to selectively induce IgG2b production.

3.3. MDP Combines with LPS to Induce Germline $\gamma 2 b$ Transcripts and Surface IgG2b Expression. The transcription of germline transcripts (GLT) is a prerequisite for subsequent Ig CSR [34-36]. Therefore, GLT expression can serve as a marker of Ig class switching. LPS induces the expression of GLT $\gamma 2 \mathrm{~b}$ as well as that of GLT $\gamma 3$ [34, $37,38]$. To evaluate the effect of MDP on LPS-induced IgG2b class switching, we examined whether LPS and MDP together induce the expression of germline $\gamma 2 \mathrm{~b}$ transcripts (GLT $\gamma 2 \mathrm{~b})$ and surface IgG2b. Resting B cells were stimulated with MDP and iE-DAP in the presence or absence of LPS, and GLT expression were measured by RT-PCR (Figure 3). LPS-induced GLT $\gamma 2 \mathrm{~b}$ expression was enhanced by MDP, whereas MDP did not affect LPSinduced GLT $\gamma 3$ and GLT $\gamma 1$ expression (Figure 3). In contrast, iE-DAP neither had any effect on LPS-induced GLT $\gamma 2 \mathrm{~b}$ expression nor on GLT $\gamma 3$ and GLT $\gamma 1$ expression. Because AID is an essential enzyme for class switching [39], we assessed its expression. MDP did not affect LPSinduced AID mRNA expression (Figure 3). In addition, MDP selectively enhanced LPS-induced surface IgG2b expression (Figure 4). MDP alone did not induce surface IgG2b expression (data not shown). Collectively, these 

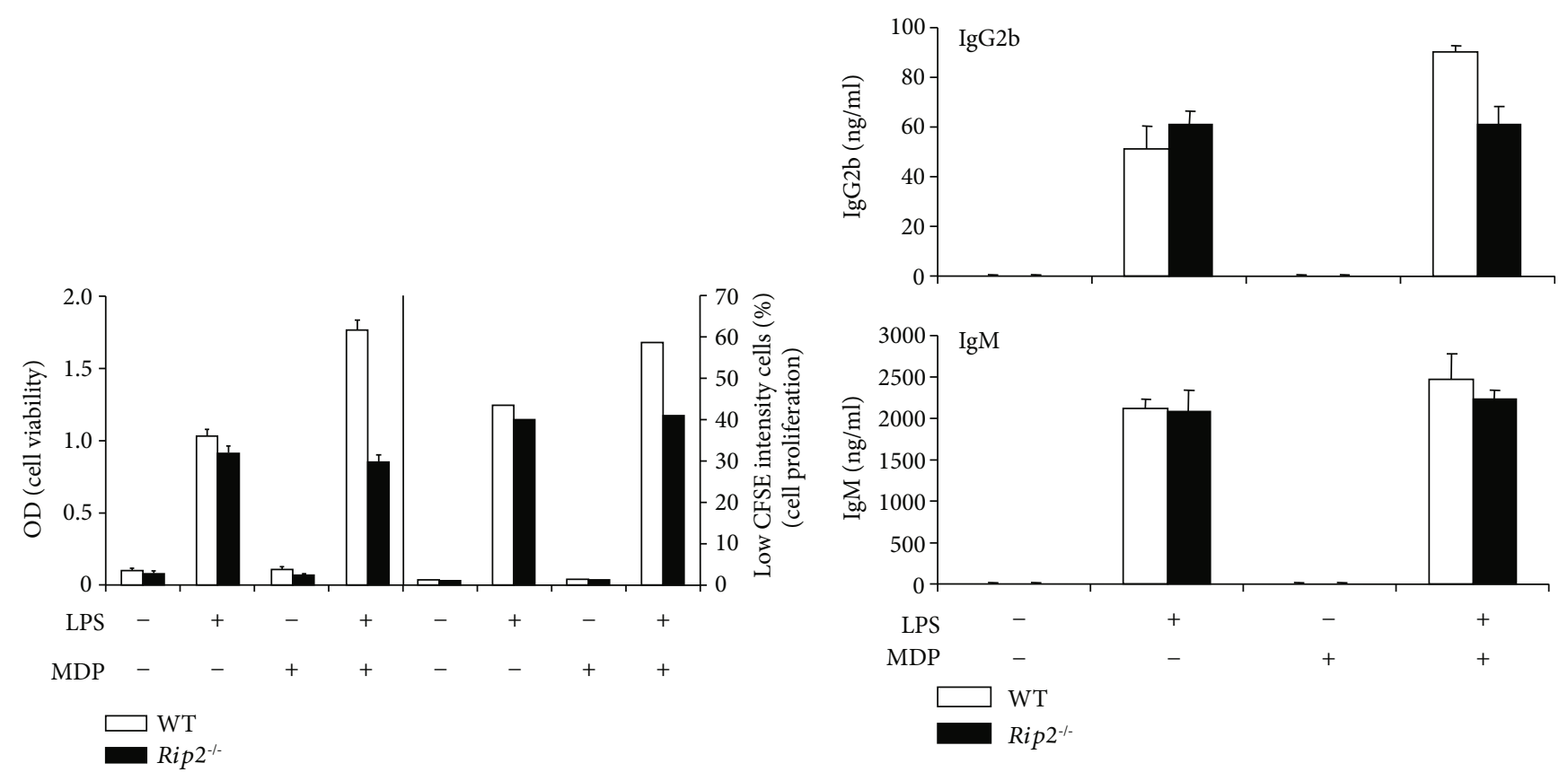

(a)

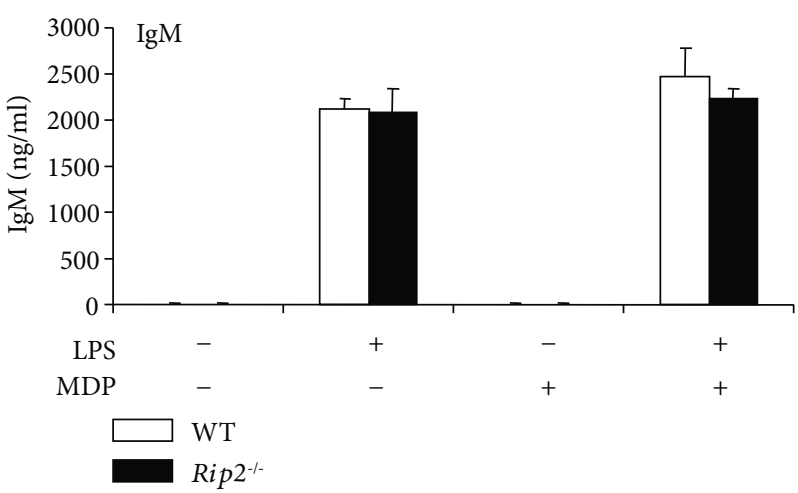

(b)

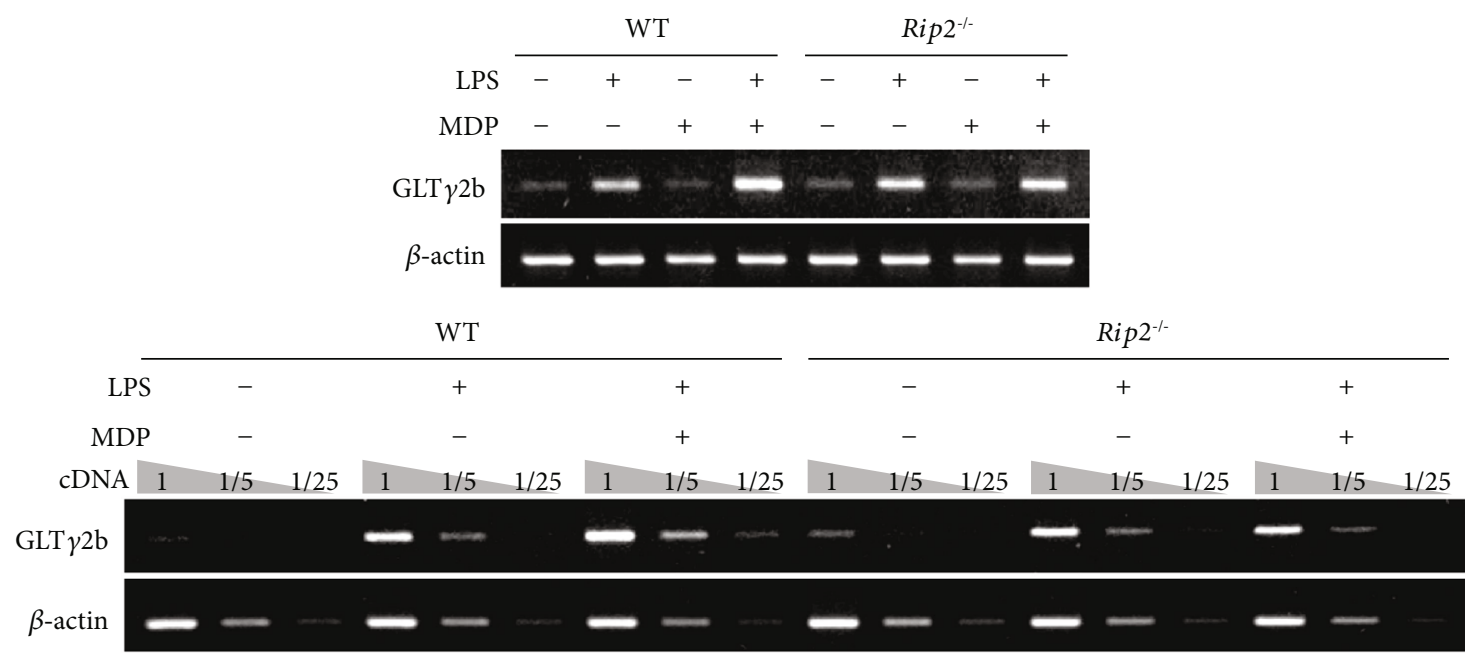

(c)

FIGURE 6: Effects of LPS and MDP on cell viability, cell proliferation, IgG2b production, and germline $\gamma 2 \mathrm{~b}$ transcripts expression in Rip2deficient B cells. Resting B cells were purified from WT and Rip2-deficient (Rip2 $2^{-1-}$ ) B cells and stimulated with MDP (10 $\left.\mu \mathrm{g} / \mathrm{mL}\right)$ and LPS $(1 \mu \mathrm{g} / \mathrm{mL})$. (a) After 2 and 3 days of culture, cell viability (OD) and proliferation were measured by EZ-Cytox assay and CFSE assay, respectively. Low CFSE intensity cell (\%) means the proportion of proliferating cells. (b) After 7 days of culture, supernatants were harvested and the levels of $\mathrm{Ab}$ production were measured using isotype-specific ELISA. Data shown are averages of triplicate cultures with SEM error bars. SEM: standard error of the mean. (c) After 2.5 days of culture, RNAs were isolated and the levels of germline $\gamma 2 \mathrm{~b}$ transcripts were measured by RT-PCR. The levels of germline $\gamma 2 \mathrm{~b}$ transcripts were measured by semiquantitative RT-PCR with $1 / 5$ and $1 / 25$ diluted cDNA (c, lower panel).

results indicate that LPS and MDP together induce $\operatorname{IgG2b}$ production through increasing IgG2b class switching.

\subsection{Combination Effect of LPS and MDP Is Abrogated in} TLR4- and Nod2-Deficient B Cells. LPS and MDP are specific agonists for TLR4 and Nod2, respectively. Therefore, we examined whether the effects of LPS and MDP on B cell responses are dependent on their specific receptors by comparing B cells from WT and TLR4-deficient $\left(T l r 4^{-/-}\right)$or
Nod2-deficient $\left(\mathrm{Nod}^{-/-}\right)$mice. WT, TLR4-, and Nod2deficient $\mathrm{B}$ cells were stimulated with MDP or iE-DAP in the presence or absence of LPS, and cell viability, cell proliferation, and $\mathrm{Ab}$ production were measured (Figure 5). In TLR4-deficient B cells, LPS did not induce cell viability and proliferation (Figure 5(a), gray bars). This finding confirms that B cell proliferation by LPS is dependent on TLR4. In Nod2-deficient B cells, MDP did not enhance LPS-induced cell viability and proliferation (Figure 5(a), black bars). This 
indicates that MDP can enhance LPS-induced B cell proliferation through Nod2. Next, we examined the effects of LPS and MDP on Ab production in TLR4- and Nod2-deficient B cells. TLR4-deficient B cells did not produce all Abs production upon stimulation of LPS (Figure 5(b)). In Nod2-deficient B cells, MDP did not increase LPS-induced IgG2b production. Furthermore, MDP did not increase LPS-induced GLT $\gamma 2 \mathrm{~b}$ expression in Nod2-deficient B cells (Figure 5(c)). These results suggest that the combined effect of LPS and MDP on B cell proliferation and IgG2b production is dependent on their receptors, TLR4 and Nod2. In addition, we investigated the effects of LPS and MDP on B cell responses in receptor-interacting protein 2 (Rip2)-deficient $\left(\right.$ Rip $2^{--}$) B cells (Figure 6), because Rip2 is a critical mediator of Nod2 signaling in innate and adaptive immune responses [40-43]. MDP neither reinforced LPS-induced cell viability nor increased cell proliferation (Figure 6(a)), IgG2b production (Figure 6(b)), or GLT $\gamma 2 \mathrm{~b}$ expression (Figure 6(c)) in Rip2-deficient B cells. Thus, Nod2-Rip2mediated signaling could cooperatively play a critical role in LPS-induced B cell responses. However, the underlying molecular mechanisms remain to be determined.

\section{Conclusions}

Our present observations demonstrate that direct stimulation of Nod2 selectively enhances TLR4 agonist LPS-induced IgG2b production by enhancing IgG2b class switching in mouse B cells. IgG2b is particularly important early in the immune response, when $\mathrm{T}$ cell support may be limited (i.e., $\mathrm{T}$-independent response), and provides early $\mathrm{Fc} \gamma \mathrm{R}$-mediated effector functions and efficient complement activation through binding on C1q [31, 44-46]. Consequently, Nod2 agonist MDP can be used as B cell adjuvant to protect from fast-replicating bacterial infection through enhancing direct $\mathrm{B}$ cell activation and IgG2b production independent of $\mathrm{T}$ cells and BCR stimulation.

\section{Abbreviations \\ TLR: Toll-like receptor \\ NLR: Nod-like receptor \\ LPS: Lipopolysaccharide \\ MDP: Muramyl dipeptide \\ Ab: Antibody \\ GLT: Germline transcripts \\ CSR: Class switch recombination.}

\section{Data Availability}

All data supporting the findings of this study, including its supplementary information files, are available from the corresponding author upon reasonable request.

\section{Disclosure}

The preliminary results of the current work have been presented as poster presentation on the $15^{\text {th }}$ International Congress of Immunology 2013 (Milan, Italy; Abstract no.:
P3.07.27). Lee Sang-Hoon's present address is the Curocell Inc., Daejeon, Republic of Korea.

\section{Conflicts of Interest}

The authors declare no financial or commercial conflict of interest.

\section{Acknowledgments}

This research was supported by the Basic Science Research Program through the National Research Foundation of Korea (NRF) funded by the Ministry of Education, Science, and Technology (MEST) (NRF-2016R1D1A1B04935588) and the Priority Research Centers Program through the NRF funded by the MEST (NRF-2017R1A6A1A03015713).

\section{Supplementary Materials}

Supplementary Table 1: RT-PCR primers. Supplementary Figure 1: Purity of resting B cells and expression of TLR4, Nod1, and Nod2 in the resting B cells. (a) Purity of isolated mouse spleen resting $\mathrm{B}$ cells $\left(\mathrm{CD} 43^{-} \mathrm{B} 220^{+}\right)$was measured using flow cytometric analysis. (b) Total RNA was isolated from the resting $\mathrm{B}$ cells and the indicated cell lines. The levels of TLR4, Nod1, and Nod2 mRNA were measured by RTPCR. (Supplementary Materials)

\section{References}

[1] N. Liu, N. Ohnishi, L. Ni, S. Akira, and K. B. Bacon, "CpG directly induces T-bet expression and inhibits IgG1 and IgE switching in B cells," Nature Immunology, vol. 4, no. 7, pp. 687-693, 2003.

[2] T. Kusunoki, M. Sugai, H. Gonda et al., "CpG inhibits IgE class switch recombination through suppression of NF $\kappa$ B activity, but not through Id2 or Bcl6," Biochemical and Biophysical Research Communications, vol. 328, no. 2, pp. 499-506, 2005.

[3] E. Shen, L. Lu, and C. Wu, "TLR7/8 ligand, R-848, inhibits IgE synthesis by acting directly on B lymphocytes," Scandinavian Journal of Immunology, vol. 67, no. 6, pp. 560-568, 2008.

[4] I. Bekeredjian-Ding and G. Jego, "Toll-like receptors - sentries in the B-cell response," Immunology, vol. 128, no. 3, pp. 311323, 2009.

[5] S. H. Lee and S. R. Park, "Toll-like receptor $1 / 2$ agonist Pam3CSK4 suppresses lipopolysaccharide-driven IgG1 production while enhancing IgG2a production by B cells," Immune Network, vol. 18, no. 1, article e10, 2018.

[6] H. K. Yoon, Y. S. Shim, P. H. Kim, and S. R. Park, "The TLR7 agonist imiquimod selectively inhibits IL-4-induced IgE production by suppressing IgG1/IgE class switching and germline $\varepsilon$ transcription through the induction of BCL6 expression in B cells," Cellular Immunology, vol. 338, pp. 1-8, 2019.

[7] B. S. Seo, S. H. Lee, J. E. Lee, Y. C. Yoo, J. Lee, and S. R. Park, "Dectin-1 stimulation selectively reinforces LPS-driven IgG1 production by mouse B cells," Immune Network, vol. 13, no. 5, pp. 205-212, 2013.

[8] B. S. Seo, H. Y. Park, H. K. Yoon, Y. C. Yoo, J. Lee, and S. R. Park, "Dectin-1 agonist selectively induces IgG1 class switching by LPS-activated mouse B cells," Immunology Letters, vol. 178, pp. 114-121, 2016. 
[9] S. Minguet, E. P. Dopfer, C. Pollmer et al., "Enhanced B-cell activation mediated by TLR4 and BCR crosstalk," European Journal of Immunology, vol. 38, no. 9, pp. 2475-2487, 2008.

[10] E. J. Pone, H. Zan, J. Zhang, A. Al-Qahtani, Z. Xu, and P. Casali, "Toll-like receptors and B-cell receptors synergize to induce immunoglobulin class-switch DNA recombination: relevance to microbial antibody responses," Critical Reviews in Immunology, vol. 30, no. 1, pp. 1-29, 2010.

[11] E. Boeglin, C. R. Smulski, S. Brun, S. Milosevic, P. Schneider, and S. Fournel, "Toll-like receptor agonists synergize with CD40L to induce either proliferation or plasma cell differentiation of mouse B cells," PLoS One, vol. 6, no. 10, article e25542, 2011.

[12] S. Jain, S. B. Chodisetti, and J. N. Agrewala, "CD40 signaling synergizes with TLR-2 in the BCR independent activation of resting B cells," PLoS One, vol. 6, no. 6, article e20651, 2011.

[13] E. J. Pone, Z. Xu, C. A. White, H. Zan, and P. Casali, "B cell TLRs and induction of immunoglobulin class-switch DNA recombination," Frontiers in Bioscience, vol. 17, no. 7, pp. 2594-2615, 2012.

[14] E. J. Pone, Z. Lou, T. Lam et al., "B cell TLR1/2, TLR4, TLR7 and TLR9 interact in induction of class switch DNA recombination: modulation by BCR and CD40, and relevance to Tindependent antibody responses," Autoimmunity, vol. 48, no. 1, pp. 1-12, 2015.

[15] E. A. Hayashi, S. Akira, and A. Nobrega, "Role of TLR in B cell development: signaling through TLR4 promotes B cell maturation and is inhibited by TLR2," Journal of Immunology, vol. 174, no. 11, pp. 6639-6647, 2005.

[16] E. J. Pone, J. Zhang, T. Mai et al., "BCR-signalling synergizes with TLR-signalling for induction of AID and immunoglobulin class-switching through the non-canonical NF$\kappa \mathrm{B}$ pathway," Nature Communications, vol. 3, no. 1, p. 767, 2012.

[17] L. Y. Cohen and M. A. Parant, "Differential regulation of surface immunoglobulin expression by various muramyl dipeptides in a murine pre-B cell line," Immunology Letters, vol. 45, no. 3, pp. 210-214, 1995.

[18] T. Petterson, J. Jendholm, A. Mansson, A. Bjartell, K. Riesbeck, and L. O. Cardell, "Effects of NOD-like receptors in human B lymphocytes and crosstalk between NOD1/NOD2 and tolllike receptors," Journal of Leukocyte Biology, vol. 89, no. 2, pp. 177-187, 2011.

[19] L. A. J. O'Neill, "Editorial: Synergism between NOD-like receptors and Toll-like receptors in human B lymphocytes," Journal of Leukocyte Biology, vol. 89, no. 2, pp. 173-175, 2011.

[20] M. S. Lee and Y. J. Kim, "Signaling pathways downstream of pattern-recognition receptors and their cross talk," Annual Review of Biochemistry, vol. 76, pp. 447-480, 2007.

[21] D. M. Underhill, "Collaboration between the innate immune receptors dectin-1, TLRs, and Nods," Immunological Reviews, vol. 219, pp. 75-87, 2007.

[22] K. Dolasia, M. K. Bisht, G. Pradhan, A. Udgata, and S. Mukhopadhyay, "TLRs/NLRs: shaping the landscape of host immunity," International Reviews of Immunology, vol. 37, no. 1, pp. 3-19, 2018.

[23] J. H. Fritz, S. E. Girardin, C. Fitting et al., "Synergistic stimulation of human monocytes and dendritic cells by Toll-like receptor 4 and NOD1- and NOD2-activating agonists," European Journal of Immunology, vol. 35, no. 8, pp. 2459-2470, 2005.
[24] W. H. Tsai, D. Y. Huang, Y. H. Yu, C. Y. Chen, and W. W. Lin, "Dual roles of NOD2 in TLR4-mediated signal transduction and -induced inflammatory gene expression in macrophages," Cellular Microbiology, vol. 13, no. 5, pp. 717-730, 2011.

[25] H. Kim, Q. Zhao, H. Zheng, X. Li, T. Zhang, and X. Ma, “A novel crosstalk between TLR4- and NOD2-mediated signaling in the regulation of intestinal inflammation," Scientific Reports, vol. 5, no. 1, article 12018, 2015.

[26] G. Janossy, J. Snajdr, and M. Simak-Ellis, "Patterns of Blymphocyte gene expression elicited by lipopolysaccharide mitogen," Immunology, vol. 30, no. 6, pp. 799-810, 1976.

[27] A. Poltorak, X. He, I. Smirnova et al., "Defective LPS signaling in $\mathrm{C} 3 \mathrm{H} / \mathrm{HeJ}$ and $\mathrm{C} 57 \mathrm{BL} / 10 \mathrm{ScCr}$ mice: mutations in Tlr4 gene," Science, vol. 282, no. 5396, pp. 2085-2088, 1998.

[28] D. Yuan and E. S. Vitetta, "Structural studies of cell surface and secreted IgG in LPS-stimulated murine B cells," Molecular Immunology, vol. 20, no. 4, pp. 367-375, 1983.

[29] C. Esser and A. Radbruch, "Immunoglobulin class switching: molecular and cellular analysis," Annual Review of Immunology, vol. 8, pp. 717-735, 1990.

[30] C. M. Snapper and J. J. Mond, "Towards a comprehensive view of immunoglobulin class switching," Immunology Today, vol. 14, no. 1, pp. 15-17, 1993.

[31] E. K. Deenick, J. Hasbold, and P. D. Hodgkin, "Switching to IgG3, IgG2b, and IgA is division linked and independent, revealing a stochastic framework for describing differentiation," The Journal of Immunology, vol. 163, no. 9, pp. 47074714, 1999.

[32] Q. Pan-Hammarstrom, Y. Zhao, and L. Hammarstrom, "Class switch recombination: a comparison between mouse and human," Advances in Immunology, vol. 93, pp. 1-61, 2007.

[33] F. J. Quintana, A. Solomon, I. R. Cohen, and G. Nussbaum, "Induction of IgG3 to LPS via toll-like receptor 4 co-stimulation," PLoS One, vol. 3, no. 10, article e3509, 2008.

[34] E. Severinson, C. Fernandez, and J. Stavnezer, "Induction of germ-line immunoglobulin heavy chain transcripts by mitogens and interleukins prior to switch recombination," European Journal of Immunology, vol. 20, no. 5, pp. 10791084, 1990.

[35] J. Stavnezer, "Immunoglobulin class switching," Current Opinion in Immunology, vol. 8, no. 2, pp. 199-205, 1996.

[36] J. Stavnezer, "Molecular processes that regulate class switching," Current Topics in Microbiology and Immunology, vol. 245, no. 2, pp. 127-168, 2000.

[37] S. Lutzker, P. Rothman, R. Pollock, R. Coffman, and F. W. Alt, "Mitogen- and IL-4-regulated expression of germ-line Ig $\gamma 2 \mathrm{~b}$ transcripts: Evidence for directed heavy chain class switching," Cell, vol. 53, no. 2, pp. 177-184, 1988.

[38] P. Rothman, S. Lutzker, B. Gorham, V. Stewart, R. Coffman, and F. W. Alt, "Structure and expression of germline immunoglobulin $\gamma^{3}$ heavy chain gene transcripts: implications for mitogen and lymphokine directed class-switching," International Immunology, vol. 2, no. 7, pp. 621-627, 1990.

[39] M. Muramatsu, K. Kinoshita, S. Fagarasan, S. Yamada, Y. Shinkai, and T. Honjo, "Class switch recombination and hypermutation require activation-induced cytidine deaminase (AID), a potential RNA editing enzyme," Cell, vol. 102, no. 5, pp. 553-563, 2000.

[40] A. I. Chin, P. W. Dempsey, K. Bruhn, J. F. Miller, Y. Xu, and G. Cheng, "Involvement of receptor-interacting protein 2 in 
innate and adaptive immune responses," Nature, vol. 416, no. 6877, pp. 190-194, 2002.

[41] K. Kobayashi, N. Inohara, L. D. Hernandez et al., "RICK/Rip2/CARDIAK mediates signalling for receptors of the innate and adaptive immune systems," Nature, vol. 416, no. 6877, pp. 194-199, 2002.

[42] J. G. Magalhaes, J. Lee, K. Geddes, S. Rubino, D. J. Philpott, and S. E. Girardin, "Essential role of Rip2 in the modulation of innate and adaptive immunity triggered by Nod1 and Nod2 ligands," European Journal of Immunology, vol. 41, no. 5, pp. 1445-1455, 2011.

[43] Q. Gong, Z. Long, F. L. Zhong et al., "Structural basis of RIP2 activation and signaling," Nature Communications, vol. 9, no. 1, article 4993, 2018.

[44] R. R. McKendall and W. Woo, "Murine IgG subclass responses to herpes simplex virus type 1 and polypeptides," The Journal of General Virology, vol. 69, no. 4, pp. 847-857, 1988.

[45] S. A. da Silveira, S. Kikuchi, L. Fossati-Jimack et al., "Complement activation selectively potentiates the pathogenicity of the IgG2b and IgG3 isotypes of a high affinity anti-erythrocyte autoantibody," The Journal of Experimental Medicine, vol. 195, no. 6, pp. 665-672, 2002.

[46] A. M. Collins, "IgG subclass co-expression brings harmony to the quartet model of murine IgG function," Immunology and Cell Biology, vol. 94, no. 10, pp. 949-954, 2016. 


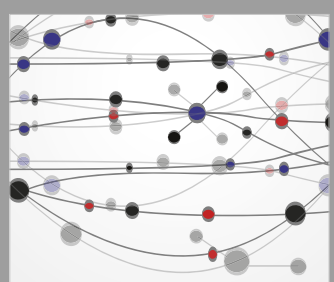

The Scientific World Journal
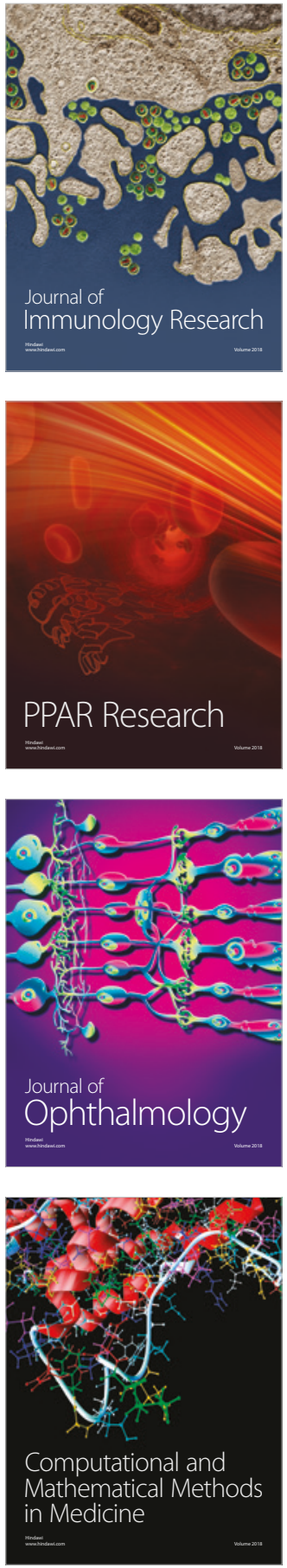

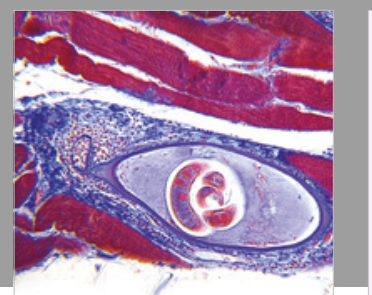

Gastroenterology Research and Practice

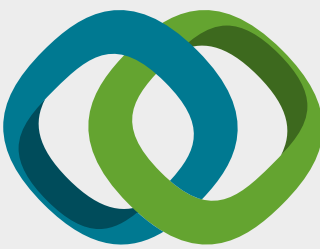

\section{Hindawi}

Submit your manuscripts at

www.hindawi.com
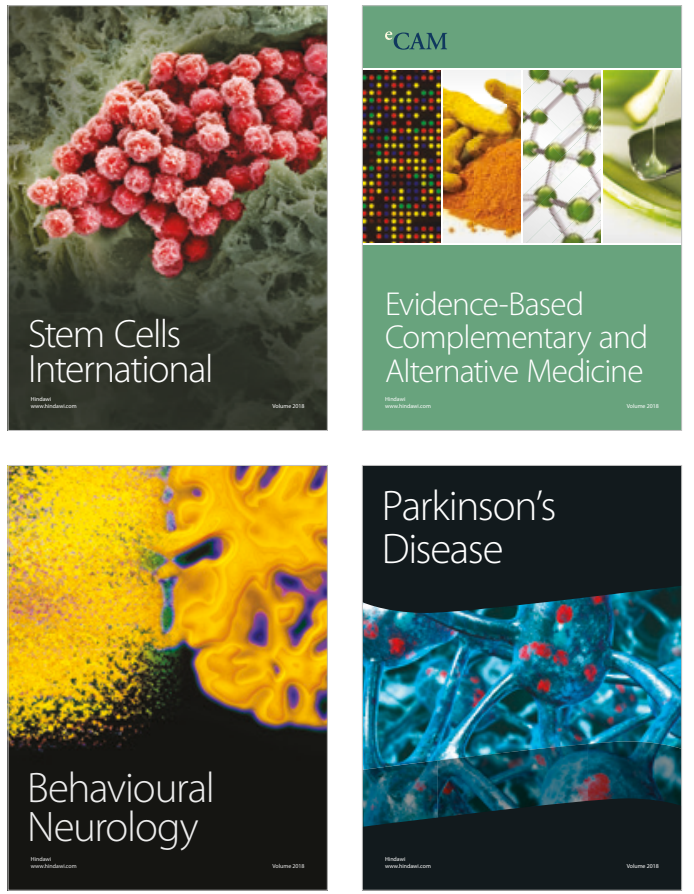

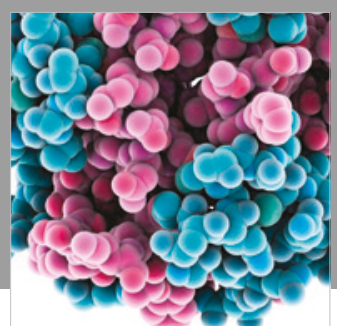

ournal of

Diabetes Research

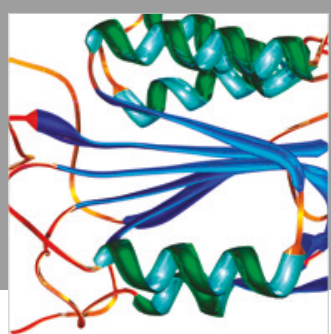

Disease Markers
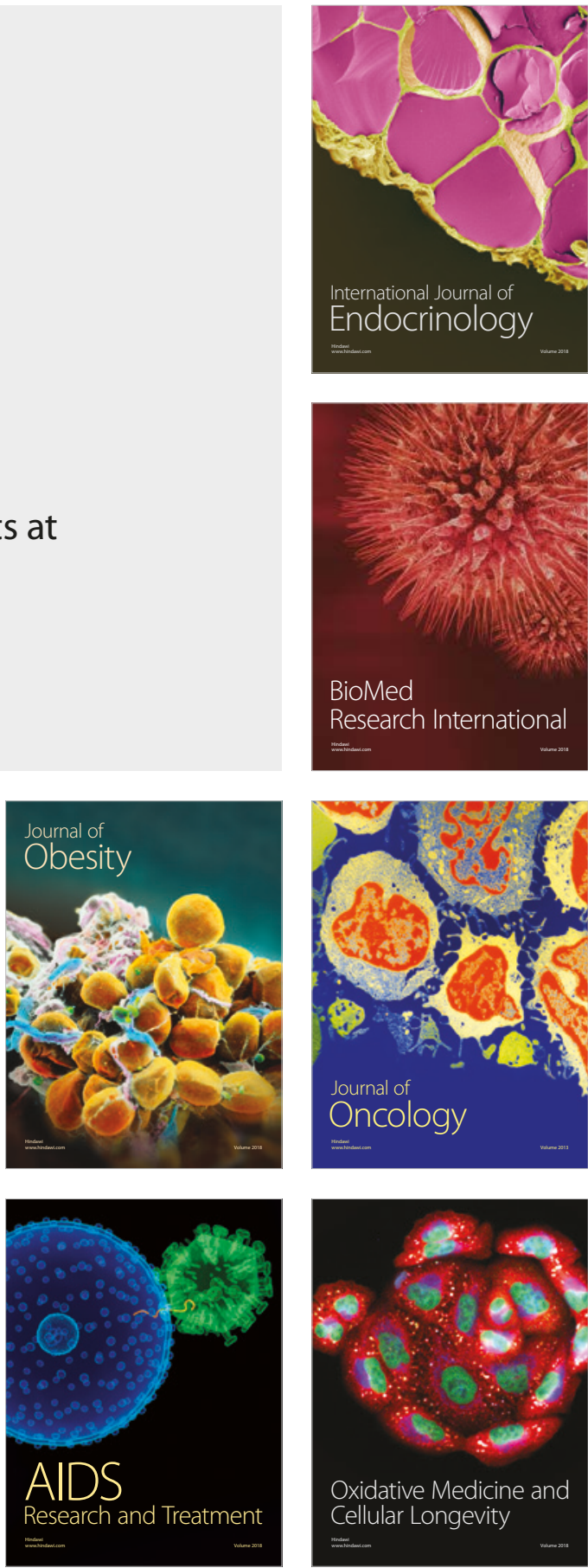